\title{
Resenhas
}

\section{PAEG e Real - dois planos que mudaram a economia brasileira}

\author{
Alkimar R. Moura (org.) \\ Rio de Janeiro: FGV Editora, 2007.
}

O conjunto de artigos organizados por Alkimar Ribeiro Moura visando à analise do PAEG (Plano de Ação Econômica do Governo), elaborado pela dupla Campos-Bulhões, e o Plano Real, tem o seu mérito refletido no próprio subtítulo: foram dois planos que alteraram a economia brasileira e isto pelo simples fato de terem sido os mais coerentes em termos de elaboração e de aplicação na nossa realidade.

$\mathrm{O}$ primeiro desses artigos "O PAEG e a Política Econômica nos anos 60 e 70", de autoria de Affonso Celso Pastore e Maria Cristina Pinotti, procura analisar a trajetória histórica desse plano ressaltando seus benefícios iniciais decorrentes da reforma tributária e da reforma bancária, esta com a criação do BACEN, como também mediante a introdução da indexação dos ativos financeiros, permitindo que se instituísse uma intermediação financeira baseada em ativos de vencimento de prazo mais longo. Pastore e Pinotti observam, e creio que este é um ponto importante do artigo por eles apresentado, que o sucesso dessas alterações criou uma certa inércia em termos de política econômica, suscitando uma opção por uma política antiinflacionária gradualista e a generalização da indexação como uma forma de conviver com a inflação. De outro lado, este aspecto positivo do plano teve seus inconvenientes: teria minado a capacidade das autoridades monetárias de combater a elevação dos preços da economia. Este fator, juntamente com uma política monetária expansionista iniciada em 1967, quando o governo optou pelo combate à inflação através do controle de preços, teria con- tribuído para a erosão inicial dos efeitos positivos do Plano. Pastore e Pinotti apresentam ainda outras variáveis para que isto acontecesse: a adesão ao regime de minidesvalorizações cambiais e o engajamento em um programa de investimento financiado pelo endividamento externo.

Pode-se em um primeiro momento discordar da conclusão desses autores de que, em ultima instância, o que determinou o fim do PAEG foi um regime fiscal baseado em imposto inflacionário (p. 93), porém, de outro lado, deve-se reconhecer o mérito desse artigo ao chamar a atenção para o processo dinâmico que limita o alcance de qualquer política econômica, na medida em que sua aplicação altera a realidade em que ela é aplicada. Assim, tal análise se afasta da hipótese inadequada de que há uma política econômica definitiva, que possa ser considerada como um análogo de um modelo físico, que por suas leis intrínsecas seria algo pronto e definitivo.

Deixando de lado os aspectos mais técnicos dessa análise, é exatamente esse aspecto positivo do artigo de Pastore e Pinotti que é severamente criticado pelos comentários apresentados por Fernando de Holanda Barbosa, que seguem ao artigo mencionado. Para este autor não há evidências empíricas que justifiquem a idéia de que o PAEG, por seus mecanismos, teria apresentado em si os mecanismos de sua própria destruição $\mathrm{e}$, isto, não porque o PAEG tenha sido um plano excelente, mas justamente o contrário, isto é, por que seria um plano limitado desde o seu início, por basear-se principalmente no mecanismo de indexação como uma forma de convivência com 
a inflação e pelo seu caráter gradualista. A meu ver alguns reparos poderiam ser feitos às críticas de Barbosa, inicialmente por não reconhecer o processo dinâmico e contraditório a que está sujeita toda a implementação de uma política econômica; segundo, por considerar que todo o problema inflacionário decorreu da falta de uma política coerente de controle da oferta monetária, conseqüência do gradualismo; e finalmente por não considerar o grande mérito da política Campos-Bulhões de, através da indexação, criar as condições do desenvolvimento de um mercado de ativos de longo prazo.

Outra contribuição para a coletânea organizada por Alkimar Moura é o artigo de Eliana Cardoso, "A inflação no Brasil”, que faz um retrospecto histórico do processo inflacionário, desde o início da república, com o processo do "encilhamento", decorrente da expansão do crédito e da especulação no mercado acionário. Analisa os diferentes programas de estabilização, ortodoxos e heterodoxos, detendo-se especialmente nos programas de congelamento de preços e no bloqueio dos ativos monetários no período Collor. Procura em seguida explicar o sucesso do Plano Real pelos seus aspectos ortodoxos e heterodoxos. Os primeiros, no início do Plano, por um elevado superávit orçamentário e uma política monetária restritiva e os aspectos heterodoxos pela introdução de uma moeda virtual e mediante regras de conversão de salários e contratos. Segundo a autora, as limitações desse plano decorreram da adoção de uma âncora cambial combinada com desequilíbrios fiscais que, em conjunto, levaram a uma valorização cambial acompanhada de juros elevados, que inevitavelmente acarretariam uma desvalorização brusca da moeda, como ocorreu no início de 1999, com os conseqüentes desequilíbrios macroeconômicos dela resultantes.

A meu ver a contribuição que melhor preenche os objetivos da coletânea é o artigo "Trinta anos combatendo a inflação no Brasil: do PAEG ao Plano Real”, de autoria de Albert Fishlow, fundamentalmente por chamar a atenção para os elementos da natureza institucional, e não apenas para os mecanismos econômicos envolvidos em tais planos. A importância disto fica clara quando lembra a observação de Roberto Campos, ao justificar as linhas gerais do PAEG: "não é fácil mudar costumes e atitudes, muito menos quando estes costumes e atitudes provêm de pessoas que lucram com a inflação [...] (assim) o principal objetivo do governo Castelo Branco não era a estabilização, mas sim fazer o capitalismo funcionar". Assim discorda de Pastore e Pinotti, que vêem uma continuidade entre o PAEG e fonte primária de importantes reformas que influenciaram a atividade econômica subseqüente, como o novo sistema de tributação sobre o valor agregado e o sistema de indexação.

Outro ponto importante da contribuição de Fishlow é o de mostrar a limitação da hipótese monetarista na explicação de certos aspectos da política antiinflacionária, ao chamar a atenção para o quebra-cabeças da persistência da inflação na segunda metade dos anos 1960, apesar da baixa taxa de crescimento da produção e da redução do déficit público em termos de percentual do produto. Passou de $4.2 \%$ em 1963 para 1.1\% em 1966. Na verdade segundo aquele autor, a análise dava uma atenção muito limitada ao papel da elevação dos custos influenciando o "pass-through" subseqüente pelas empresas. Ao não colocar tal problema, os monetaristas não se perguntaram se a "inflexibilidade observada da inflação às políticas monetárias e fiscais restritivas poderia demandar reduções severas e desnecessárias na produção se fosse mantida a restrição indefinitivamente" (p.155). Observou ainda que apenas em 1967 uma correlação positiva entre queda da utilização e uma queda nos preços pôde ser observada e acrescenta que a "ortodoxia funciona, porém a um alto preço para a produção".

Comparando o PAEG com o Plano Real, após identificar os pontos principais deste como apresentados por Eliana Cardoso, Fishlow observa que o PAEG escolheu uma abordagem gradualista rejeitando explicitamente um processo de congelamento de salários, colocando-se a favor da necessidade de reduzir o consumo público para aumentar a poupança ressaltando a impossibilidade de eliminar o déficit público imediatamente e a necessidade de uma inflação corretiva para ajustar os preços públicos e a importância de se evitar efeitos negativos sobre os devedores.

Com o fim do PAEG e passada a fase de "milagre econômico", a inflação retoma a sua marcha. Com o reconhecimento de que a dificuldade em controlá-la decorria de seu caráter inercial, foi realizada uma série de planos de caráter heterodoxos, inclusive baseados no controle de preços que infelizmente não tiveram sucesso. Passou-se então, com o surgimento do Plano Real, a incorporar elementos de natureza ortodoxos 
como no PAEG, especialmente o controle do déficit público, ao qual se adicionaram elementos heterodoxos de grande originalidade e eficácia.

Assim, de acordo com o Fishlow, o Real em vez de se utilizar dos métodos heterodoxos convencionais de controles de preço para neutralizar os elementos inerciais da inflação, estabeleceu a existência de duas moedas que deveriam conviver em um certo período de tempo: a nova, que seria indexada à taxa real de câmbio ajustada diariamente, de tal modo que, gradativamente, todos os valores e preços se tornassem atrelados a ela. Neste momento a antiga moeda seria abolida. O intuito da introdução da nova moeda, a URV, seria o de permitir um processo gradual e voluntário de ajustamento de contratos e, assim, prover um mecanismo de conversão dos salários a uma moeda indexada e, portanto livre de expectativas de desvalorização. Os salários seriam fixados pela média dos salários dos últimos quatro meses, o que evitaria o seu ajustamento no seu valor máximo, ou seja, no pico.

De outro lado, de forma análoga à longa permanência da indexação no PAEG, a insistência na utilização de uma âncora cambial levou ao enfraquecimento do Plano Real. Daí observa Fishlow que um dos erros deste foi "não usar políticas fiscais e monetárias como a âncora contínua que garantiria o fim das altas taxas de inflação. Ao invés disso foi usada uma taxa semifixa de câmbio para garantir a estabilidade dos preços". O resultado disto como todos sabem foi um câmbio valorizado, que, em conjunto com as crises internacionais que se dão a partir de 1994, levou à crise cambial de 1998, a qual levou o Brasil a recorrer ao FMI e à conseqüente abrupta desvalorização do real em inícios de 1999.

Uma outra área de comparação do Plano Real com o PAEG, segundo Fishlow, está relacionada à distribuição da renda, pois ao contrário do que aconteceu com a concentração de renda entre 1960 e 1970 decorrente da política salarial do governo nos anos de 1965 e 1966, o Plano Real beneficiou os mais pobres, pois o declínio da inflação teve o efeito positivo de aumentar o salário real da população.

Finalmente, ressaltando os efeitos benéficos da estabilização do Real, Fishlow chama a atenção do que este é sem dúvida o primeiro passo para se conseguir um crescimento econômico sustentado, que, no entanto, deve ser complementado por um aumento da taxa interna de poupança, permanência das condições recentes de expansão das exportações, um maior investimento em educação, na ampliação e melhoria dos serviços públicos e uma maior valorização da área social.

Luiz Antonio de Oliveira Lima

Professor da Escola de Administração de Empresas de São Paulo - FGV 